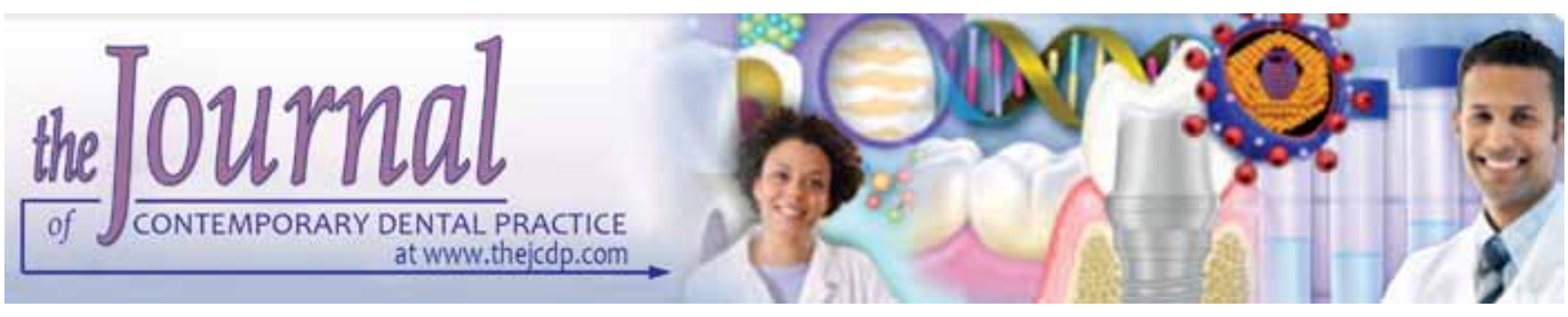

\title{
Relevance of Routine Blood Pressure Assessment among Dental Patients in Lagos, Nigeria
}

Kehinde Adesola Umeizudike, Patricia Omowunmi Ayanbadejo, Theophilus Ifeanyichukwu Umeizudike Gerald Ikenna Isiekwe, Kofoworola Olaide Savage

\section{ABSTRACT}

Aim: To determine the relevance of routine blood pressure (BP) measurement in patients attending the dental clinic.

Materials and methods: This was a retrospective survey of patients who attended the dental clinic in the Preventive Dentistry Department of a tertiary Hospital in Lagos, Nigeria over an eighteen month period. Data retrieved from the patient's hospital records included age, sex, BP and history of hypertension. Data was analyzed using Epi info 2011 package. $p$-value $<0.05$ was considered statistically significant.

Results: A total of 1910 patients' records were assessed. Females represented $53.4 \%(n=1020)$ of the study population. The mean age was $37.1 \pm 15.0$ years (range $18-88$ years). The prevalence of hypertension was $39.9 \%(n=763)$. Hypertension was stage 1 in $25.5 \%$, stage 2 in $9.8 \%$ and severe in $4.6 \%$ of the dental patients. Past medical history of hypertension was obtained for 952 patients (49.8\%). Of the 763 patients with high blood pressure, $14.8 \%$ had a known history of hypertension, while $42.1 \%$ were previously undiagnosed $(p<0.0001)$. Systolic and diastolic BP increased with increasing age $(p<0.05)$ and was significantly higher in males than females $(p<0.05)$.

Conclusion: The high prevalence of hypertension noted among the study population with its potential consequence during dental procedures makes the measurement of blood pressure a valuable assessment in a dental clinic.

Clinical significance: The high prevalence of hypertension particularly the previously undiagnosed cases among the dental patients highlights the relevance of routine blood pressure assessment prior to dental procedures in contemporary dental practice, so as to minimize the potential complications that could occur.

Keywords: Relevance, Hypertension, Blood pressure, Dental patients.

How to cite this article: Umeizudike KA, Ayanbadejo PO, Umeizudike TI, Isiekwe GI, Savage KO. Relevance of Routine Blood Pressure Assessment among Dental Patients in Lagos, Nigeria. J Contemp Dent Pract 2013;14(6):1145-1150.

Source of support: Nil

Conflict of interest: None

\section{INTRODUCTION}

High blood pressure (HBP) popularly referred to as hypertension is the major risk factor associated with cardiovascular diseases. Hence, it is often called the 'silent killer' because of this risk. It also remains the commonest noncommunicable disease globally. ${ }^{1,2}$ According to the American Heart Association (2008), high blood pressure (classified as $140 / 90 \mathrm{~mm} \mathrm{Hg}$ or above) is still the most common primary diagnosis in the United States, affecting nearly one out of every three Americans.

The picture is not much different in Nigeria, the most populous Black Country in Africa. Measuring a person's blood pressure (BP) is the principal screening method for hypertension. ${ }^{3}$ As most Nigerians do not routinely take their BP readings, hypertension is undiagnosed being often asymptomatic. Therefore, many hypertensive individuals are unaware of their condition. ${ }^{1}$ The studies carried out on the general population have reported the prevalence of hypertension to be high, ranging from 12.4 to $34.8 \%$ in Nigeria. ${ }^{4-12}$ This relatively high prevalence coupled with the fact that it is largely undiagnosed in several individuals ${ }^{3}$ may have serious implications in patients, particularly those seeking dental treatment in the clinic.

This category of patients whilst undergoing complex dental treatment may be potentially at risk of developing some complications such as myocardial infarctions or stroke in the dental chair due to fluctuations in their BP. ${ }^{13,14}$ Furthermore, there is also the possibility of an increase of the BP by local anesthetic agents containing epinephrine which may result in an arrhythmia, a dangerous development in patients with hypertension. These risks are well documented in the literature. ${ }^{14}$

In spite of these risks; few studies have documented the profile of hypertension among dental patients in Nigeria, which may indicate that routine BP check may not be a 
consistent practice in most dental clinics in Nigeria. A study by Ojehanon et $\mathrm{al}^{15}$ in Benin city, Nigeria found a prevalence of hypertension among dental patients to be $19.7 \%$, while $10.3 \%$ of patients seen were found to have elevated BPpreviously undiagnosed with hypertension. Sproat et al ${ }^{16}$ while screening patients attending a city dental practice in London discovered a prevalence of hypertension to be $39 \%$ with just $18 \%$ known to be previously hypertensive. The objective of the present study was to determine the relevance of routine BP measurement in adult patients attending the dental clinic.

\section{MATERIALS AND METHODS}

This was a retrospective, cross-sectional Survey of dental patients who had attended the Preventive Dentistry Clinic of the Lagos University Teaching Hospital over an 18 months period. This hospital serves as a referral center for many patients in Lagos, the commercial capital city of Nigeria. Lagos is a Cosmopolitan city that is home to about 16 million Nigerians. It is one of the fastest growing cities in the world, with a projected population of over 20 million by 2020. The hospital is the older of the two teaching hospitals in the state and serves the middle and lower class. The study group consisted of adult dental patients ( $>18$ years of age) who came for dental check-up, and those referred from other peripheral hospitals between 2010 and 2012. This clinic serves both new and old patients coming for dental treatment within the hospital.

Data retrieved included the age, sex, blood pressure (BP) and known history of hypertension from the patients' hospital records. Trained dental personnel, using a standard mercury sphygmomanometer measured the BP. Patients who were found to have elevated BP of $\geq 140 / 90 \mathrm{~mm} \mathrm{Hg}$, had their BP re-checked to confirm the elevated BP after resting for 2 to 5 minutes.

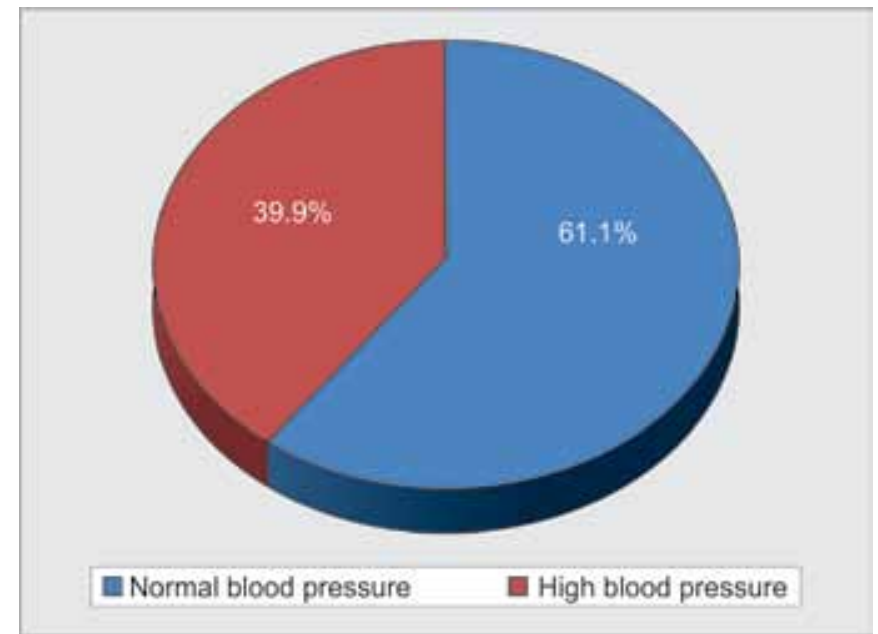

Fig. 1: Distribution of normal vs high blood pressure in dental patients
The National Institute for Health and Clinical Excellence (NICE) clinical guideline 127 Hypertension: clinical management of primary hypertension in adults was utilized to categorise patients into three groups. ${ }^{17}$ Stage 1 hypertension: clinic BP is $140 / 90$ to $159 / 99 \mathrm{~mm} \mathrm{Hg}$. Stage 2 hypertension: clinic BP is $160 / 100$ to $179 / 109 \mathrm{~mm} \mathrm{Hg}$. Severe hypertension: clinic systolic BP is $180 \mathrm{~mm} \mathrm{Hg}$ or higher or clinic diastolic BP is $110 \mathrm{~mm} \mathrm{Hg}$ or higher.

The data was analyzed using Epi info 2011 package. Chi-square test was used to explore associations between the BP measured during dental visit and previous history of hypertension. $p$-values of $<0.05$ were considered statistically significant.

\section{RESULTS}

The total number of adult patients' records assessed in this study was 1910 . Their age ranged between 18 and 88 years with a mean age of $37.1 \pm 15.0$ years. Females represented $53.4 \%(\mathrm{n}=1020$, mean age $37 \pm 14.9$ years $)$ and males $46.6 \%(n=890$, mean age $37.2 \pm 15.1$ years $)$ of the total study group.

The prevalence of hypertension among the dental patients was $39.9 \%(\mathrm{n}=763)$ as shown in Figure 1 .

Stage 1 hypertension was present in $25.5 \%$, Stage 2 in $9.8 \%$ and severe in $4.6 \%$ of the patients (Table 1 ). Mean systolic BP in the study population was $123.6 \pm 17.6 \mathrm{~mm} \mathrm{Hg}$, while the mean diastolic BP was $80.8 \pm 13.5 \mathrm{~mm} \mathrm{Hg}$.

Table 2 shows that the prevalence of hypertension increased significantly with increasing age group $(p=0.000)$. This is also shown by Fig. 2.

\begin{tabular}{|c|c|c|c|}
\hline $\begin{array}{l}\text { Stage of } \\
\text { Hypertension }\end{array}$ & $S B P(m m ~ H g)$ & $D B P(m m ~ H g)$ & $N(\%)$ \\
\hline Normal & $<140$ & $<90$ & $1147(60.1)$ \\
\hline $\begin{array}{l}\text { Stage } 1 \\
\text { hypertension }\end{array}$ & $140-159$ & $90-99$ & $488(25.5)$ \\
\hline $\begin{array}{l}\text { Stage } 2 \\
\text { hypertension }\end{array}$ & $160-179$ & $100-109$ & $188(9.8)$ \\
\hline $\begin{array}{l}\text { Severe } \\
\text { hypertension }\end{array}$ & $\geq 180$ & $\geq 110$ & $87(4.6)$ \\
\hline
\end{tabular}

SBP: Systolic blood pressure; DBP: Diastolic blood pressure

Table 2: Prevalence of high blood pressure by age group

\begin{tabular}{llll}
\hline $\begin{array}{l}\text { Age group } \\
\text { (years) }\end{array}$ & $\begin{array}{l}\text { Total patient } \\
\text { population }\end{array}$ & $\begin{array}{l}\text { Patients with } \\
\text { high blood } \\
\text { pressure }\end{array}$ & $\begin{array}{l}\text { Prevalence of high } \\
\text { blood pressure in } \\
\text { population }\end{array}$ \\
\hline$\leq 19$ & 80 & 11 & $13.8 \%$ \\
$20-29$ & 703 & 180 & $25.6 \%$ \\
$30-39$ & 460 & 178 & $38.7 \%$ \\
$40-49$ & 258 & 125 & $48.4 \%$ \\
$50-59$ & 204 & 128 & $62.7 \%$ \\
$\geq 60$ & 205 & 141 & $68.8 \%$ \\
\hline
\end{tabular}

$p=0.000$ 
Relevance of Routine Blood Pressure Assessment among Dental Patients in Lagos, Nigeria

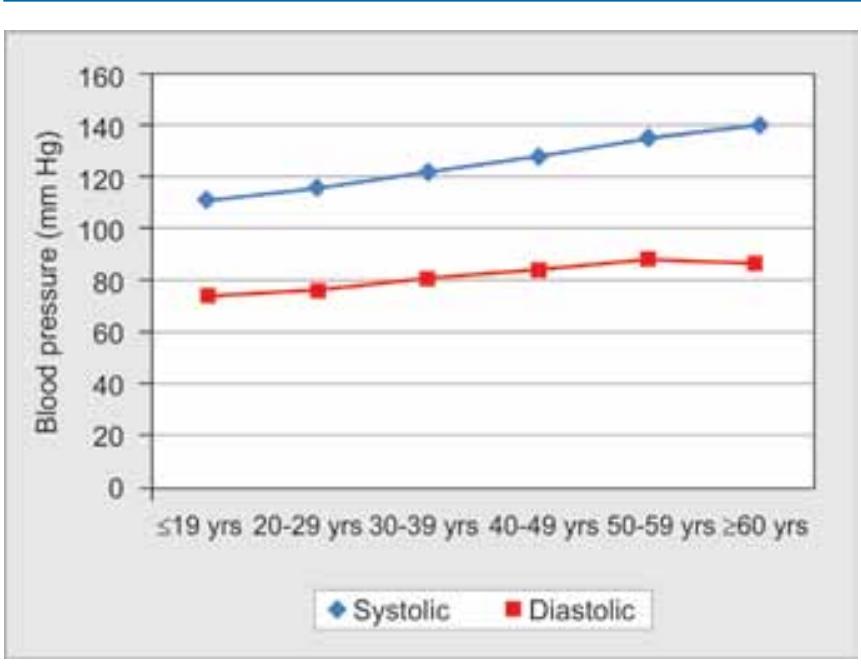

Fig. 2: Systolic and diastolic blood pressure by age group

The stages of hypertension were significantly associated with increasing age of the patients $(p=0.000)$ as represented by Table 3 .

Table 4 shows the mean BP for both systolic and diastolic BP for each gender group and age group. The mean systolic $\mathrm{BP}$ was significantly higher in males $(124.6 \pm 17.3 \mathrm{~mm} \mathrm{Hg})$ than females $(122.6 \pm 17.8 \mathrm{~mm} \mathrm{Hg})(\mathrm{T}$-test, $\mathrm{p}=0.015)$. Males also had a significantly higher mean diastolic BP than females $(82 \pm 13.7 \mathrm{~mm} \mathrm{Hg} v s 81 \pm 13.4 \mathrm{~mm} \mathrm{Hg})$ respectively (T-test, $\mathrm{p}=0.024)$. The frequency of hypertension was higher in males (41.2\%) than females (38.8\%), but was not significantly associated.

In reviewing the patients' case notes, 952 (49\%) were noted to have given a history of presence or absence of hypertension. Of these, 763 had high BP during their dental visit.

Among patients found to have a high BP during their dental visit, only $14.3 \%(n=109)$ were previously diagnosed hypertensives, $42.1 \%(\mathrm{n}=321)$ gave no history of hypertension

\begin{tabular}{lcccc}
\multicolumn{5}{c}{ Table 3: Stages of blood pressure by age group } \\
$\begin{array}{l}\text { Age group } \\
\text { (years) }\end{array}$ & Normal & Stage 1 & Stage 2 & Severe \\
$\leq 19$ & $69(86.3 \%)$ & $9(11.3 \%)$ & $1(1.3 \%)$ & $1(1.3 \%)$ \\
$20-29$ & $523(74.4 \%)$ & $136(19.3 \%)$ & $34(4.8 \%)$ & $10(1.4 \%)$ \\
$30-39$ & $282(61.3 \%)$ & $113(24.6 \%)$ & $43(9.3 \%)$ & $22(4.8 \%)$ \\
$40-49$ & $133(51.6 \%)$ & $85(32.9 \%)$ & $25(9.7 \%)$ & $15(5.8 \%)$ \\
$50-59$ & $76(37.3 \%)$ & $67(32.8 \%)$ & $39(19.1 \%)$ & $22(10.8 \%)$ \\
$\geq 60$ & $64(31.2 \%)$ & $78(38 \%)$ & $46(22.4 \%)$ & $17(8.3 \%)$ \\
\hline$p=0.0000$ & & & &
\end{tabular}

in their case notes, while the remaining $43.6 \%(n=333)$ had no documentation of the presence or absence of hypertension $(\mathrm{p}<0.0001)$.

\section{DISCUSSION}

According to the American Society of Hypertension, ${ }^{18}$ the only way hypertension can be diagnosed is by measuring a person's blood pressure. Once detected, treatment methods have been reported to reduce the risk of cardiovascular disease and fatality by as much as $30 \% .{ }^{19}$ In our study, the prevalence of hypertension among dental patients attending the dental clinic in a tertiary hospital in Lagos, South-West Nigeria was $39.9 \%$. This was quite high and alarming. This prevalence is also comparable to the $42.2 \%$ reported in a recent study by Ulasi et al. ${ }^{20}$ It could also be compared to the $32 \%$ reported by Kellogg and Dobetti ${ }^{3}$ in a similar study carried out on a Dental school patient population in the US. The value in our study and that of Ulasi et $\mathrm{al}^{20}$ are however higher than that reported in other prevalence studies in the general Nigerian population ${ }^{4-10,12}$ and among the dental patient population in Nigeria as well. ${ }^{15}$ These differences may perhaps reflect a rising prevalence in hypertension as seen globally. Other reasons could be the type of population group studied. The present study was in an urban setting which differed from the earlier studies some of which were in rural settings. This fact is supported by Addo et $\mathrm{al}^{21}$ who pointed out the higher prevalence in urban compared to rural studies.

Arguably, the effect of 'White coat hypertension' may have contributed to the elevated blood pressure in our study, particularly the anxiety associated with dental treatment. This effect however may have been minimal because our results are comparable with other prevalence studies on hypertension among the general Nigerian population. ${ }^{20}$ This high prevalence could be due to a number of factors. These include the increasing adoption of a westernized diet in developing countries like Nigeria. Other risk factors include a sedentary lifestyle, obesity, smoking, alcohol consumption and increasing age. The stress associated with living in a cosmopolitan city like Lagos is another factor that should not be overlooked in this study.

Table 4: Distribution of blood pressure by age group and gender in the study population

\begin{tabular}{|c|c|c|c|c|c|c|}
\hline \multirow[t]{2}{*}{ Age group (years) } & \multirow[t]{2}{*}{$n$} & \multicolumn{2}{|c|}{ Men $(n=890)$} & \multirow[t]{2}{*}{$n$} & \multicolumn{2}{|c|}{ Women $(n=1020)$} \\
\hline & & Systolic BP (mm Hg) & Diastolic BP $(\mathrm{mm} \mathrm{Hg})$ & & Systolic BP $(\mathrm{mm} \mathrm{Hg})$ & Diastolic BP $(\mathrm{mm} \mathrm{Hg})$ \\
\hline$\leq 19$ & 34 & $114 \pm 11.8$ & $75 \pm 12.2$ & 46 & $108 \pm 10.7$ & $73 \pm 10.3$ \\
\hline $20-29$ & 323 & $119 \pm 12.7$ & $78 \pm 11.7$ & 380 & $114 \pm 12.3$ & $75 \pm 11.2$ \\
\hline $30-39$ & 228 & $122 \pm 13.9$ & $80 \pm 12.9$ & 232 & $123 \pm 18.2$ & $81 \pm 13.7$ \\
\hline $40-49$ & 113 & $131 \pm 20.2$ & $86 \pm 15.2$ & 145 & $126 \pm 11.4$ & $83 \pm 11.4$ \\
\hline $50-59$ & 88 & $135 \pm 18.9$ & $88 \pm 15.8$ & 116 & $135 \pm 18.1$ & $88 \pm 12.6$ \\
\hline$\geq 60$ & 104 & $137 \pm 20.4$ & $86 \pm 12.9$ & 101 & $142 \pm 19.7$ & $88 \pm 14.0$ \\
\hline
\end{tabular}


Few studies in Nigeria have indeed examined the prevalence of hypertension and its potential effects on general health in a dental clinic setting. ${ }^{15,20}$ In a similar study carried out among dental patients at a tertiary institution in Edo state Nigeria, the prevalence of hypertension in the study population was 19.7 and $10.3 \%$ representing patients with previously undiagnosed hypertension. ${ }^{15}$

The high prevalence of high blood pressure in our study among the dental patients is a source of concern because of the potential risks and complications that have been reported to occur during some dental procedures. These include hemodynamic and cardiovascular changes particularly with the use of adrenalin-containing local anesthesia. ${ }^{23}$ The health of hypertensive dental patients may be endangered whenever they undergo any dental treatment without the dentist's adequate consideration for their medical history and current medications. The stress associated with any dental procedure coupled with the effect of adrenaline-containing local anesthetic agents may complicate their dental treatment by increasing their already elevated blood pressure, causing acute severe life-threatening complications, such as cardiac arrest or cerebrovascular accident. ${ }^{24,25}$

The blood pressure fluctuations may occur regardless of the type of dental treatment. ${ }^{26,27}$ Although, a recent study in a tertiary hospital in Lagos Nigeria reported hemodynamic changes to be within normal range in dental patients with controlled hypertension during tooth extraction when injected with $2 \%$ lignocaine with adrenaline. ${ }^{22}$

Unfortunately, most hypertensive patients are not well controlled. This fact is supported by the literature which revealed that only a small percentage of hypertensive patients achieve an optimal control of their blood pressure. ${ }^{5,11}$ It therefore implies that there is a higher chance that most of the dental patients with a history of hypertension would be poorly controlled and this could have serious implications for the dentist during patient's treatment. This information regarding the patient's control of their blood pressure was however not provided in our study.

The present study also highlighted the proportion $(14.3 \%)$ of patients with hypertension who had been previously diagnosed and were aware of their history of hypertension. This percentage was quite low compared to the overall prevalence $(39.9 \%)$ of hypertension in our study. This thus buttresses the fact that detection of high blood pressure is low among dental patients in developing countries. This low level of detection and consequent control of hypertension has been attributed to scarce resources and inadequate healthcare provision in sub-Saharan Africa. ${ }^{28}$ Despite the public enlightening programs carried out by the government, the public awareness still appears to be on the low side. These screening programs should be continued more frequently with the additional provision of antihypertensive drugs for free or at subsidized cost.

The prevalence of hypertension increased incrementally from $13.8 \%$ in $\leq 19$ years old group to $68.8 \%$ in the $\geq 60$ years old age group. This rising prevalence of hypertension with increasing age in both men and women in our study is not a new finding and is also supported by the American Society of Hypertension. ${ }^{18}$ It is consistent with the global trend in the prevalence of hypertension. Furthermore, hypertension has been identified as the most common systemic disease in elderly dental patients. ${ }^{29}$ This may thus imply that older patients would have a higher risk of developing untoward complications than younger dental patients. Males had overall higher blood pressure levels than females in this study. When compared within different age groups in the patients with hypertension, this difference was however not significant.

The level of importance attached by dentists and students to hypertension among dental patients appears inadequate particularly past medical history and the documentation of such. This was reflected by the wide gap in the data between blood pressure assessment and record of previous history of hypertension in patient's case notes. This was due to the discovery that 958 (50.2\%) patients did not have records of their past medical history of hypertension. Either, they did not know their hypertension status, or knew and declined to give the information. This is not surprising as some people in this environment are sentimental and have cultural or religious beliefs which may prevent them from undergoing regular blood pressure checks or admitting they have hypertension fearing that it might get worse. This is further buttressed by Ekwunife et al ${ }^{11}$ who identified the reason given by most of the people who declined to participate in their study, which was the fear of being diagnosed with hypertension once their blood pressure was measured. Some dentists may have also overlooked this record during their history taking. This gap in information was a constraint and a limitation in our study which we hope to address in future studies. In view of this, we recommend that dental students and dentists should always obtain a history of hypertension and also endeavor to document it in the patient's case notes, given the high prevalence that this study revealed. Other limitations of the study are the retrospective nature which reduces reliability of the medical records. The check of elevated BP to determine the diagnosis of hypertension should have been at another visit documenting a sustained elevation in BP. On the other hand, one of the strengths of the study is the large sample size. Following the limitations of clinic BP measurement in making a diagnosis of hypertension, it may be necessary 
to use ambulatory or home BP measurements to confirm elevated BP found during a clinic visit. This will certainly remove the white-coat hypertension effect. Another future direction to this study is the need to correlate hypertension with periodontal disease among dental patients attending the clinic, because of the recent link of periodontal disease to cardiovascular disease.

Dentists should also pay attention to patients on diuretics which have additional anti cholinergic effects and cause reduced salivary flow predisposing the patient to root caries. The importance of regular assessment of the blood pressure of dental patients at each visit, past medical history and complete documentation in patients' case notes cannot be overemphasized.

\section{CONCLUSION}

Hypertension is highly prevalent among routine dental patients. There is therefore the need to perform routine blood pressure assessment on these patients before dental procedures.

\section{CLINICAL SIGNIFICANCE}

The importance of routine blood pressure measurements for all patients attending the dental clinic is highlighted in this study as shown by the high prevalence of hypertension particularly the previously undiagnosed cases. This will help to minimize the potential risks associated with dental procedures in patients with uncontrolled high blood pressure.

Dentists should also educate their patients on the health risk factors associated with hypertension, and help to promote healthy lifestyle changes.

\section{REFERENCES}

1. Kearney PM, Whelton M, Reynolds K, Whelton PK, He J. Worldwide prevalence of hypertension: a systematic review. Journal of Hypertension 2004;22(1):11-19.

2. Kearney PM, Whelton M, Reynolds K, Muntner P, Whelton PK, He J. Global burden of hypertension: analysis of worldwide data. Lancet 2005;365(9455):217-223.

3. Kellogg SD, Gobetti JP. Hypertension in a Dental School Patient Population. J Dent Ed 2004;68:956-964.

4. Owoaje EE, Rotimi CN, Kaufman JS, Tracy J, Cooper RS. Prevalence of adult diabetes in Ibadan, Nigeria. East Afr Med J 1997;74:299-302.

5. Cooper R, Rotimi C, Ataman S, McGee D, Osotimehin B, Kadiri S, Muna W, Kingue S, Fraser H, Forrester T, et al. The prevalence of hypertension in seven population of West African origin. Am J Public Health 1997;87(2):160-168.

6. Kadiri S, Walker O, Salako BL, Akinkugbe O. Blood pressure, hypertension and correlates in urbanized workers in Ibadan, Nigeria: a revisit. J Hum Hypertens 1999;13:23-27.

7. Lawoyin TO, Asuzu MC, Kaufman J, Rotimi C, Owoaje E, Johnson L, Cooper R. Prevalence of cardiovascular risk factors in an African, urban inner city community. West Afr J Med 2002;21:208-211.

8. Adedoyin RA, Mbada CE, Balogun MO, Martins T, Adebayo, RA, Akintomide A. Prevalence and pattern of hypertension in a semi-urban community in Nigeria. Eur J Cardiovasc Prev Rehab 2008;15(6):683-687.

9. Ogbagbon EK, Okesina AB, Biliaminu SA. Prevalence of hypertension and associated variables in paid workers in Ilorin, Nigeria. Niger J Clin Pract 2008;11(4):342-346.

10. Nigerian Heart Foundation: Federal Ministry of Health and Social Services. Health behaviour monitor among Nigerian adult population. 2003. Available at: http://www.who.int/chp/ steps/2003_STEPS_Report_Nigeria.pdf

11. Ekwunife OI, Udeogaranya PO, Nwatu IL. Prevalence, awareness, treatment and control of hypertension in a Nigerian population. Health 2010;2(7):731-735.

12. Ekwunife OI, Aguwa CN. A meta analysis of prevalence rate of hypertension in Nigerian populations. Journal of Public Health and Epid 2011;3(13):604-607.

13. Herman WW, Konzelman Jr WW, Prisant M. New national guidelines on hypertension: a summary for dentistry. J Am Dent Assoc 2004;135:576-584.

14. Thompson AL, Collins MA, Downey MC, Herman WW, Konzelman JL Jr, Ward ST, Hughes CT. Prevalence and Severity of Hypertension in a Dental Hygiene Clinic. J Contemp Dent Practice 2007;(8)3:13-20.

15. Ojehanon PI, Akhionbare O. Hypertension among dental patients attending tertiary health institution in Edo State, Nigeria. Niger J Clin Pract 2007;10(3):220-223.

16. Sproat C, Beheshti S, Harwood AN, Crossbie D. Should we screen for hypertension in general dental practice? Br Dent J 2009 Sep 26;207(6):275-277.

17. National Institute for Health and Clinical Excellence. Hypertension: clinical management of primary hypertension in adults (update). Clinical guideline $127.2011 \mathrm{http} / /$ guidance. nice.org.uk/CG127

18. American Society of Hypertension. Patient information guide to understanding hypertension. New York 1999-2000.

19. Fahey TP, Peters TJ. What constitutes controlled hypertension? Patient based comparison of hypertension guidelines. Br Med J 1996;313(7049):93-96.

20. Ulasi II, Ijoma CK, Onwubsere BJC, Arodiwe E, Onodugo O, Okafor C. High prevalence and low awareness of hypertension in a market population in enugu, Nigeria. Int J Hypertens 2011; Article ID 869675.

21. Addo J, Smeeth L, Leon DA. Hypertension in sub-Saharan Africa: a systematic review. Hypertension 2007;50(6): 1012-1018.

22. Ogunlewe MO, James O, Ajuluchukwu NA, Ladeinde AL, Adeyemo WL, Gbotolorun OM. Evaluation of haemodynamic changes in hypertensive patients during tooth extraction under local anaesthesia. West Indian Med J 2011;60(1):91-95.

23. Matsumura K, Miura K, Takata Y, Kurokawa H, Kajiyama M, Abe I, Fujishima M. Changes in blood pressure and heart rate variability during dental surgery. Am J Hypertens 1998;11: 1376-1380.

24. Glick M. New guidelines for prevention, detection, evaluation and treatment of high blood pressure. J Am Dent Assoc 1998; 29(11):1588-1594.

25. Gungormus M, Buyukkurt MC. The evaluation of changes in Blood pressure and pulse rate of hypertensive patient during tooth extraction. Acta Med Austriaca 2003;30:127-129. 
26. Gortzak RA, Abraham-lnpijn L, Oosting J. Blood pressure response to dental check-up: a continuous noninvasive registration. Gen Dent 1991;39:339-342.

27. Brand HS, Gortzak RA, Palmer-Bouva CC, Abraham RE, Abraham Inpijn L. Cardiovascular and neuroendocrine responses during acute stress induced by different types of dental treatment. Int Dent J 1995;45(1):45-48.

28. Pobee JOM. Community-based high blood pressure programs in sub-Saharan Africa. Ethnic Disparities 1993;3:38-45.

29. Umina M, Nagao M. Systemic diseases in elderly dental patients. Int Dent J 1993;43:213-218.

\section{ABOUT THE AUTHORS}

\section{Kehinde Adesola Umeizudike (Corresponding Author)}

Lecturer, Consultant Periodontologist, Department of Preventive Dentistry, Faculty of Dental Sciences, College of Medicine, University of Lagos, Nigeria, Phone: 2348055451018, e-mail: kumeiz09@gmail. com

\section{Patricia Omowunmi Ayanbadejo}

Senior Lecturer, Consultant Periodontologist, Department of Preventive Dentistry, Faculty of Dental Sciences, College of Medicine University of Lagos, Nigeria

\section{Theophilus Ifeanyichukwu Umeizudike}

Consultant Nephrologist, Department of Medicine (Nephrology Unit) Lagos State University Teaching Hospital, Nigeria

\section{Gerald Ikenna Isiekwe}

Lecturer, Consultant Orthodontist, Department of Child Dental Health, Faculty of Dental Sciences, College of Medicine, University of Lagos, Nigeria

\section{Kofoworola Olaide Savage}

Professor of Periodontology, Department of Preventive Dentistry Faculty of Dental Sciences, College of Medicine, University of Lagos Nigeria 